\title{
La técnica moderna: entre serenidad (Gelassenheit) y dispositivo (Ge-stell): Martin Heidegger a cuarenta años de su muerte
}

\author{
The Modern Technique: Between Serenity (Gelassenheit) And \\ Enframing (Ge-Stell): Martin Heidegger forty years after his \\ dead
}

JORGE LUIS QUINTANA MONTES*

\begin{abstract}
Resumen: El artículo se concentra en el análisis y crítica de Martin Heidegger a la técnica moderna. Para esto, se encuentra costituido de tres momentos esenciales: en primer lugar, mostramos al dispositivo (Ge-stell) como la esencia de la técnica moderna, y por tanto, como una forma histórica de la verdad ( $\dot{\alpha} \lambda \eta \dot{\theta \varepsilon \iota} \alpha$ ). Segundo: exponemos la serenidad (Gelassenheit) como el modo heideggeriano de decir sí y no al dominio técnico. En este sentido, y siguiendo a Klaus Held, el momento final del artículo muestra a la Gelassenheit como una forma contemporánea de la moderación ( $\sigma \omega \phi \varrho 0 \sigma u ́ v \eta)$ aristotélica.

Palabras clave: Heidegger, Técnica moderna, Dispositivo (Ge-stell), Serenidad (Gelassenheit),

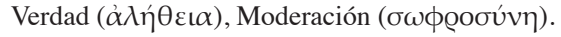

\begin{abstract}
Abstrac: The article focuses on the Martin Heidegger's analysis and critique about the modern technique. For this, the paper is made up of three essential moments: first, we show the Enframing (Ge-stell) like the essence of the modern technique, and thus, like an historical kind of truth $(\dot{\alpha} \lambda \eta \dot{\eta} \varepsilon\llcorner\alpha)$. Second: we expose the Serenity (Gelassenheit) as the heidegegrian way for said yes and no to the technical domain. In this way, and following to Klaus Held, the third and final moment of the article shows the Gelassenheit as a contemporary kind of aristotelian moderation ( $\sigma \omega \phi \varrho о \sigma u ́ v \eta)$.

Keywords: Heidegger, Modern technique, Enframing (Ge-stell), Serenity (Gelassenheit), Truth

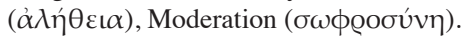

Recibido: 25/09/2016. Aceptado: 03/07/2017.

* Benemérita Universidad Autónoma de Puebla. Contacto: revistahodos@gmail.com 
La estructura de emplazamiento [Ge-stell] deforma el resplandecer y el prevalecer de la verdad. El sino que destina a la solicitación es por ello el peligro extremo. Lo peligroso no es la técnica. No hay nada demoníaco en la técnica, lo que hay es el misterio de su esencia. La esencia de la técnica, como un sino del hacer salir lo oculto, es el peligro.

Martin Heidegger

Realmente es verdad que el hombre de la era técnica está pro-vocado de un modo especial y sobresaliente al desocultar. Este concierne inmediatamente a la naturaleza como al principal almacén de existencias de energías.

Martin Heidegger

El motivo que nos reúne en este evento, es pensar la obra de Heidegger a cuarenta años de su muerte ${ }^{1}$. En este sentido, volver su trabajo implica, a nuestro juicio, poner de relieve el carácter actual de la reflexión heideggeriana; esto es, pensar nuestra coordenada histórica con el filósofo de Messkirch. Así las cosas, y pensando con y desde Heidegger $a$ cuarenta años de su muerte, el objetivo que dirige la realización de la presente ponencia es exponer los rasgos críticos que subyacen al análisis heideggeriano de la técnica moderna y la salida ofrecida ante los peligros que genera su uso no controlado. Para dar alcance a este fin, el texto seguirá así: 1) caracterización heideggeriana de la técnica en relación con el concepto de verdad $(\dot{\alpha} \lambda \eta \dot{\theta} \theta \varepsilon\llcorner\alpha), 2)$ la salida heideggeriana ante los peligros surgidos de la técnica moderna: serenidad y apertura al misterio, y 3) la serenidad, como mesura, en clave ético-ambiental.

\section{La técnica y el pensar histórico en la obra de Heidegger}

La reflexión desplegada por Heidegger a partir de la década de los treinta, tomó como uno de sus ejes fundamentales pensar de manera radical el acontecer histórico en el aquí y ahora. Este pensar ontohistórico heideggeriano se edifica desde un horizonte fenomenológico: la premisa husserliana de "volver a las cosas mismas" fue llevada a su límite por Heidegger al poner en cuestión la cosa misma sobre la cual debía volverse el interrogar filosófico. De esta manera, lo puesto de relieve por Heidegger se refiere al ámbito de donación del fenómeno esencial, es decir, apunta a dejar ser aquello que se oculta y desoculta al pensar originario. Se dirige a la cosa misma del pensar. El pensar que se abre al ámbito de la donación del

1 Este artículo condensa los elementos centrales de la ponencia presentada en el marco del I Coloquio Nacional de la Sociedad Iberoamericana de Estudios Heideggerianos (SIEH): Heidegger a cuarenta años de su muerte, el cual tuvo lugar los días 4 y 5 de Abril de 2016 en la Benemérita Universidad Autónoma de Puebla, México. 
ser es llamado por Heidegger meditación. En el texto titulado La época de la imagen del mundo, Heidegger presenta el doble aspecto que constituye el meditar histórico. En primer lugar, y como ya se indicó, meditación es la vuelta sobre el ser, en tanto que se asume éste como la cosa digna de ser pensada: "Para la meditación, el ser es siempre lo más digno de ser cuestionado" (Heidegger, 1995, 79). En segunda instancia, el pensar meditativo se vuelve sobre el modo en que se dona e interpreta el ser en determinada época histórica, con el fin de esclarecer dicho momento de donación. A juicio de Heidegger, indican Xolocotzi, Gibu, Huerta y Veraza (2014), la posibilidad misma de la historia se funda en la apertura del ser y en el preguntar por él. La modernidad, entendida epocálmente a la luz del pensar que interroga por el ser, es una era carente de historicidad en la medida en que se ha edificado sobre la base de la técnica moderna, el consumo y la industria. Por lo tanto, el olvido del ser que tiene lugar en la modernidad, a causa del imperio de la racionalidad tecnológica, es la causa misma de la ausencia de historicidad. Poner en marcha el pensar meditativo es la única manera de "volver" a la historia:

Ahora bien ¿cómo acontece nuestro ámbito histórico? (...) La modernidad es un tiempo que se reitera a sí mismo, a la manera de una incesante renovación, el imparable productivismo de la «sociedad industrial» -en palabras de Heidegger-, todo lo cual constituye la situación de la pérdida de la historicidad (...) La posibilidad de que volvamos a tener una historia coincide, entonces, para Heidegger, con la posibilidad de que seamos capaces para un verdadero cuestionamiento (...) Así la cosas, el preguntar radical abriría, a contracorriente de la modernidad, el tener lugar de la historia... (Xolocotzi, Gibu, Huerta y Veraza, 2014, 124-125).

De forma muy superficial podríamos señalar éste como el contexto temático en que se inscribe el análisis heideggeriano de la técnica. Por cuestiones de tiempo, no resulta prudente ni extendernos ni entrar aquí en detalles que desbordan el pequeño objetivo que nos hemos propuesto; antes bien, preferimos iniciar desde este momento la presentación de la caracterización heideggeriana de la técnica moderna. Vale realizar la siguiente aclaración: como nuestra intención es pensar la esencia de la técnica moderna como Ge-stell, en relación con la Serenidad, nos concentraremos no Los aportes a la filosofía (1936), sino en La pregunta por la técnica. Esta elección responde a una razón estrictamente metodológica, a saber: que en el texto de 1936, el análisis de la técnica moderna tiene lugar bajo el concepto de Maquinación (Machenschaft) -entendida como capacidad creadora de los aparatos, su hacederuría: "Maquinación como dominio del hacer y de la hechura (...) En la maquinación se encuentra a la vez la interpretación cristiano-bíblica del ente como ens creatum" (Heidegger, 2003, 117)-. Así, y aunque con ésta se exponga el antecedente analítico de la Ge-stell, como indican Xolocotzi et. al., la Ge-stell es tematizada de forma precisa en la conferencia del año 53. El enfoque ofrecido desde Los aportes y desde la lección de 1937-38, revela rasgos distintivos y de absoluta riqueza temática respecto de la técnica moderna, tales como 
lo gigantesco (Riesenhasfte) ${ }^{2}$ o la vivencia (Erlebnis) ${ }^{3}$; sin embargo, dada la orientación que dirige nuestra investigación, no haremos referencia a estos aspectos.

\subsection{En torno a la esencia de la técnica}

Indiquemos el punto de partida de Heidegger: el buscar fenomenológico, en su interrogar más propio, no fija la mirada en el conjunto de los aparatos técnicos que hacen parte del horizonte de la vida cotidiana del sujeto. Para el filósofo de Messkirch, el buscar debe poner su atención no en el aparato, sino en la esencia misma de la técnica moderna ${ }^{4}$. En este sentido, Heidegger no se pregunta por cuáles objetos del mundo son resultado del despliegue técnico. Su buscar trasciende este límite, intentado poner a la luz lo que es la técnica en un sentido

2 Lo gigantesco (Riesenhafte) apunta al primado de lo cuantitativo. Así, lo medible ya no es visto como una expresión más del ente -al lado de sus otras cualidades, sino que la cantidad misma; esto es, la calculabilidad de los objetos, deviene su cualidad principal: "Ya no es lo objetivo re-presentable de un "cuantitativo" ilimitado, sino la cantidad como cualidad" (Heidegger, 2003, 121). En este sentido, lo gigantesco no se reduce al simple hecho de que todo lo técnico se expresa en las grandes construcciones o maquinarias, sino -como dijimos - en que el cálculo es la cualidad propia de todo ente. Por ello, y tal cual se indica en La época de la imagen del mundo, lo gigante se expresa de igual manera en lo minúsculo, en las cifras diminutas, pues ellas son, por sí mismas, expresiones de lo cuantificable de lo ente: “...lo gigantesco se muestra en el sentido de lo cada vez más pequeño. Estamos pensando en las cifras de la física atómica. Lo gigantesco se afirma bajo una forma que precisamente parece hacerlo desaparecer: en la aniquilación de las grandes distancias del avión, en la representación en toda su cotidianidad, producida a placer y sin ningún esfuerzo, de mundos extraños y lejanos gracias a la radio. Pero creer que lo gigantesco es simplemente el vacío extendido hasta el infinito de lo que solo es cuantitativo, es pensar de manera demasiado superficial. Tampoco se piensa con el suficiente alcance cuando se opina que lo gigantesco, bajo la forma de esas interminables cosas nunca vistas, nace únicamente de una ciega pasión por la exageración y la superación. Y no se piensa en lo absoluto cuando se cree haber explicado el fenómeno de lo gigantesco con la palabra 'americanismo'. Lo gigantesco es más bien aquello por medio de lo cual lo cuantitativo se convierte en una cualidad propia y, por lo tanto, en una manera especialmente señalada de lo grande" (Heidegger, 1995, 77-78. Las cursivas son nuestras)

3 Con la noción del viven-ciar (Er-leben) o la vivencia (Erlebnis), Heidegger hace referencia a un fenómeno propio de la época técnica, caracterizado por el cómo de la relación del hombre con lo ente. Específicamente hablando, apunta al modo en que el ente deviene, en último término, en representación del sujeto: "Referir al ente como re-presentado a sí como centro de referencia y así incluirlo en la "vida". Por qué el hombre como "vida" (animal rationale) (;ratio - re-presentar!)” (Heidegger, 2003, 115). De este modo representacional de la relación se desprende lo que llama Heidegger el encantamiento. En este punto resultan absolutamente esclarecedoras, para comprender esta categoría de los Beiträge, las lecciones del 37-38. En dichas lecciones comenta Heidegger que lo propio de la vivencia apunta a una especie de experiencia de la espectacularidad. Es el hombre puesto de cara ante el aparato técnico de lo deslumbra y que todo lo hace evento: "Cuanto más implacables son las maniobras de la razón y su cálculo, tanto más fuerte y multitudinario es el alarido por la «vivencia». Ambos se incrementan y enredan mutuamente. Aún más: las maniobras, por ejemplo los logros gigantescos de la técnica, llegan a ser ellos mismos la «vivencia» más grande, y las vivencias buscan la forma de la maniobra. Una pelea de box es una «vivencia», pero seguramente no para los boxeadores; estos no tienen vivencia alguna, pero por lo menos se limitan a boxear; el «vivenciar» reside en los espectadores, y lo vivido es una maniobra del espectáculo de «gran prducción»" (Heidegger, 2008, 132).

4 Cfr. Másmela, Carlos (2009): "Por eso resulta paradójico que en el intento de pensar la técnica nos encontremos con algo así como el Ge-stell. Tenemos que preguntar de inmediato, cómo algo que no tiene nada de técnico puede ser el concepto directriz a partir del que Heidegger accede a la técnica" (65) "Heidegger, el ensamblaje del Ge-stell en la técnica moderna” En: Xolocotzi, Ángel y Godina, Célida (Coord.) La técnica ¿orden o desmesura?, México: Los libros de Homero. 
esencial: "La técnica no es lo mismo que la esencia de la técnica. Cuando buscamos la esencia del árbol, tenemos que darnos cuenta de que aquello que prevalece en todo árbol como árbol no es a su vez un árbol que se pueda encontrar entre los árboles” (Heidegger, 1994, 9).

Para lograr su objetivo, la investigación emprendida es desarrollada en una lectura que parte del análisis de la técnica antigua. Dicho con puntualidad, Heidegger expone la esencia

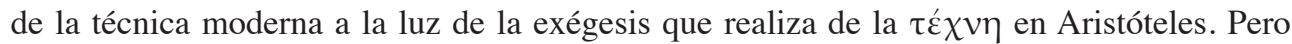
¿cómo emprende la mencionada reflexión? El primer movimiento analítico que realiza, es cuestionarse por el modo en que se presenta el fenómeno técnico ordinariamente. Así, descubre que la técnica es asumida a partir de una caracterización antropológico-instrumental de la misma, entendiendo el carácter antropológico como un simple hacer del hombre. Entre tanto, el carácter instrumental hace referencia al hecho de que se ve en la técnica un simple medio que permite al individuo dar alcance a determinados fines.

La mencionada caracterización antropológico-instrumental de la técnica no da con el aspecto originario que busca Heidegger. Sin embargo, sería inadecuado pensar que, en la medida en que la consideración antropológico-instrumental no expone la esencia de lo técnico, Heidegger se decide a abandonarla como punto de partida. Heidegger es consciente de que la esencia de la técnica no es simplemente la relación medio-fin, pero no por esto desecha sin más esta caracterización. De esta forma, en la medida en que resulta correcta, intenta esclarecer el aspecto ontológico de la técnica que late de fondo en la concepción antropológico-instrumental. Y ¿qué es aquello que se oculta en la concepción instrumental de la técnica? Para Heidegger la respuesta es evidente: la causalidad. Comenta el fenomenólogo alemán a este respecto: "También el fin según el cual se determina el modo de los medios vale como causa. Donde se persiguen fines, se emplean medios; donde domina lo instrumental, allí prevalece la condición de causa, la causalidad" (Heidegger, 1994, 11).

Dicho esto, Heidegger inicia una presentación de la teoría aristotélica de las cuatro causas. El cuádruple aspecto que expone la causalidad, tiene como primer elemento a la causa material. Con ésta, se apunta a la materia que constituye la creación de un artesano. El segundo momento de la cuádruple articulación es la forma, pensada como el aspecto universal de los objetos; es decir, el cĩoos. La tercera causa, es la final. Ésta indica el fin último, el "para qué" del ente. De esta manera, la causalidad articula no sólo el "de qué" está hecho el ente ni el aspecto del mismo, sino que presupone-además- el telos de su realización. Finalmente, aparece la causa "eficiente", la cual es la que da lugar a la concreción del ente producido en la articulación de las restantes tres causas. La causa eficiente apunta al artesano que vincula la materia y la forma dentro del horizonte del "para qué" del ente.

Ahora bien ¿cuál es el cimiento último de la cuádruple articulación causal? Lo ontológicamente originario aquí es el traer al aparecer mismo; es decir, la producción. Así la cosas,

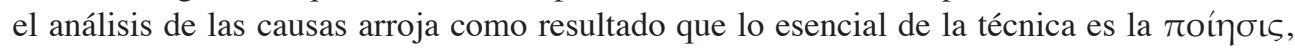
es la posibilidad de traer el ente a la presencia. De este modo, y en tanto que la técnica

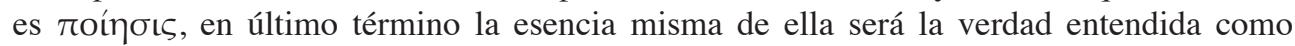
$\dot{\alpha} \lambda \eta \dot{\theta \varepsilon \iota} \alpha$, en tanto en cuanto sólo es posible el traer a la luz al ente, en la medida en que la producción lo saca de lo oculto:

El traer-ahí-delante acaece de un modo propio sólo en tanto que lo ocultado viene a lo desocultado. Este venir descansa y vibra en lo que llamamos salir de lo oculto. Los 
griegos tienen para esto la palabra alétheia. Los romanos la tradujeron por veritas. Nosotros decimos «verdad», y habitualmente la entendemos como corrección del representar (...) La técnica es un modo del hacer salir de lo oculto. La técnica esencia en la región en la que acontece el hacer salir lo oculto y el estado de desocultamiento, donde acontece la alétheia, la verdad (Heidegger, 1994, 15-16).

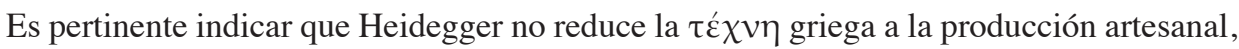

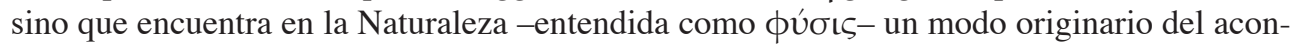
tecer la verdad, debido al hecho de que todo brotar de la Naturaleza es un brotar a partir de sí misma que va de lo oculto a lo no oculto.

Una vez esbozados los rasgos característicos de la técnica dentro del horizonte del pensar griego, hay que poner de relieve el siguiente interrogante en tanto que se torna hilo conductor de las próximas consideraciones: ¿Cae la técnica moderna dentro de los mismos límites ontológicos de la técnica antigua? Es decir ¿corresponde a la técnica moderna el ser un modo particular de acaecer el desocultar? De golpe, podríamos vernos arrojados ante el hecho "evidente" de que la técnica moderna no comparte ningún rasgo con la técnica antigua. Sin embargo, el filósofo de Messkirch aborda de manera radical las preguntas planteadas.

Su punto de partida para dar respuesta a los interrogantes, es la puesta en escena de un fenómeno originariamente vinculado con el acaecimiento moderno de la técnica, a saber: la ciencia moderna. Heidegger no cuestiona el vínculo existente entre ciencia y técnica; antes bien, lo afirma con la intención de abrir el trasfondo ontológico desde el cual se edifica dicha relación; pero ¿Cómo acontece la relación entre ambos? A primera vista, lo que se pone ante nuestra mirada es lo siguiente: si y solo si porque tuvo lugar como hecho histórico, en primera instancia, la matematización de la naturaleza gracias a la tradición galileana, pudo advenir a la historia -en segunda instancia- el acontecimiento de la técnica moderna, entendida como reificación del aparato y la maquinaria. No obstante, y en contra de la simpleza y evidencia de lo dicho en el discurso historiográfico, Heidegger invierte la relación ciencia-técnica moderna. De esta forma, concluye que, sólo porque late de fondo en la modernidad la técnica moderna y su esencia, es que pudo tener lugar el imperio de las ciencias exactas en Occidente.

Las Preguntas fundamentales de la filosofía presentan, en una especie de "breve historia crítica de la concepción de verdad", la forma en que dicha noción ha sido asumida como corrección de la proposición. La verdad, indica Heidegger en dichas lecciones (invierno 1937/1938), habita en el juicio para Aristóteles ${ }^{5}$. En consecuencia, la verdad es la corrección

5 Este curso dictado por Heidegger entre 1937 y 1938, el cual corre parejo con la redacción de los Beiträge zur philosophie, resulta de vital importancia en el intento de pensar la apropiación heideggeriana de la filosofía aristotélica, ya no en el marco de los textos tempranos, sino en el horizonte de su obra tardía. Indicativo debe ser el hecho de que, en el los límites del pensamiento ontohistórico, parece que Heidegger concentra la interpretación aristotélica del fenómeno de la verdad en un nivel predicativo. Juicio como lugar de la verdad es un vínculo originario que tiende Heidegger en su aproximación ontohistórica al Estagirita. Diríamos, siguiendo aquí en cierto sentido a Volpi (2012), que la riqueza de la interpretación aristotélica realizada por el Maestro de la Selva Negra como parte de la repetición (Wiederholung) de la tradición filosófica, emprendida durante los años veinte, queda fuera de juego. Cobra sentido - a partir de esta premisa- la interpretación volpiana que pone como núcleo temático crucial del Heidegger tardío los trabajos de Hölderlin y Nietzsche. Frente a lo que Heidegger llama "realismo crítico" en su Informe Natorp, opone una lectura más amplia del fenómeno de la 
del juicio erróneo en tanto que no corresponde con aquello que mienta. Desde Aristóteles, la verdad ha tomado la forma de corrección, para decantar históricamente en veritas y certeza. La ciencia moderna es heredera de dicha concepción de la verdad, en tanto que se encuentra atravesada por ella. Siguiendo este horizonte analítico y la premisa historiográfica, la ciencia

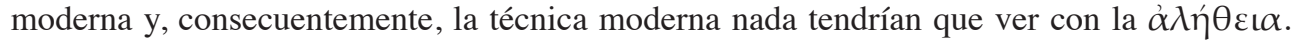
A pesar de esto, Heidegger se opone a la evidencia de la ciencia histórica apuntando que primero es la técnica moderna y luego la ciencia. En este orden de ideas, y al ser originario el fenómeno de la técnica, la verdad que habita en ella no se encuentra necesariamente reducida al ideal de certeza. Contrario a éste, afirma en La pregunta por la técnica que lo propio de la técnica moderna es la $\alpha \lambda \eta ́ \theta \varepsilon \iota \alpha$ en un modo específico de acontecer.

Con la técnica moderna impera un desocultar, por ende, es también reino de la verdad. Con todo, es un desocultar distinto al griego. El desocultar antiguo estaba materializado en la actividad productora del artesano que, en su hacer, hacía confluir los distintos modos de la causalidad. El č $\gamma_{\gamma}$ ov, lo advenido, lo desoculto en el trabajo del orfebre, era resultado

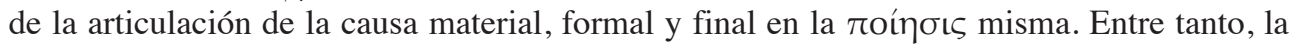
técnica moderna también trae a la luz, pero no como lo hace un orfebre que produce una copa de plata. Dicho con precisión, el desocultar propio de la técnica moderna lo que devela son las energías que se acumulan en el seno mismo de la Naturaleza. Este "sacar a la luz" las energías ocultas de la Naturaleza es el modo propio en que acontece la $\alpha \lambda \eta \dot{\theta} \theta \varepsilon \iota \alpha$ en la técnica moderna: “¿Qué es la técnica moderna? También ella es un hacer salir lo oculto (...) A una región de tierra (...) se la provoca para que saque carbón y mineral. El reino de la tierra sale de lo oculto ahora como cuenca de carbón; el suelo, como yacimiento de mineral" (Heidegger, 1994, 17).

¿Y cuál el destino de lo desocultado por el acontecer técnico moderno? Una vez es extraída la energía de la Naturaleza a través de un desvelar que violenta, eso que se extrae se transforma y se almacena, abriéndose con esto paso a la disponibilidad plena del ente.

verdad en Aristóteles. A su juicio, antes que encontrar en el Estagirita una defensa de la verdad en el ámbito judicativo, el fenomenólogo llama la atención en el hecho de que el $\lambda$ ó $\gamma$ os apofántico es, preeminentemente,

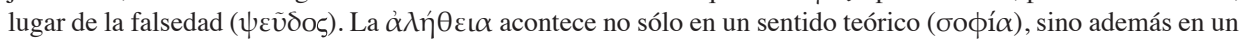

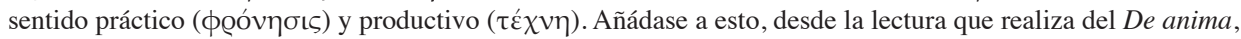
el carácter antepredicativo de la verdad, vista desde la percepción de los sensibles propios. En este orden de ideas, Heidegger parecería desconocer en sus reflexiones ontohistóricas lo que él mismo puso de relieve en sus lecciones de principios del veinte (Einfürung in die phänomenologische Forschung [GA 17], Grundbegriffe der aristotelischen philosophie [GA 18] y Platon: Sophistes [GA 19]). Podríamos decir que, en razón de la comprensión de la metafísica propia de la ontohistoria (reducción del Ser a permanente presencia y reducción

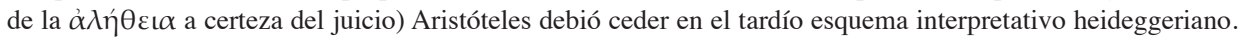
Ahora bien, y aunque sea cierto que en las lecciones del 37-38 la verdad sea pensada aristotélicamente como corrección del juicio, y aunque sea cierto también el carácter privilegiado que adquiere Hölderlin en el pensar ontohistórico, no es posible negar la vitalidad que tiene Aristóteles en la comprensión heideggeriana de la técnica. Y es que Heidegger llega -con Hölderlin- a la conclusión de que en la esencia de la técnica no habita sólo el peligro sino también lo salvador, gracias, primero, a la interpretación de la causalidad en términos aristotélicos, y -segundo- a partir de la comprensión de la actividad técnico productiva ( $\tau \dot{\varepsilon} \chi \nu \eta)$ como modo de la verdad (E.N. VI). Así, Heidegger arriba a Hölderlin, si y solo si, porque ya Aristóteles ha abonado el terreno de su comprensión de la esencia de la técnica. Resulta preeminente entonces matizar este tipo de comentarios hechos por Heidegger, leyéndolos siempre en relación, tanto con sus primeros trabajos, como con los textos posteriores a la década del treinta. 
En este proceso del acaecer técnico moderno de la verdad, Heidegger ubica la desaparición de la objetualidad de los objetos, en la medida en que todo objeto creado es simplemente objeto disponible al uso. Todo lo explotado de la Naturaleza y lo creado no es más que una mera existencia en el stock de almacenamiento. Un avión está ahí ante los ojos como objeto; sin embargo, lo que subyace ontológicamente al estar ahí del avión es que su ser objeto ha quedado reducido al simple estar disponible (Bestand) ante la necesidad del viaje:

El hacer salir de lo oculto que domina por completo a la técnica moderna tiene el carácter del emplazar, en el sentido de la provocación. Este acontece así: la energía oculta en la Naturaleza es sacada a la luz, a lo sacado a la luz se lo transforma, lo transformado es almacenado, a lo almacenado a su vez se lo distribuye, y lo distribuido es nuevamente conmutado. Sacar a la luz, transformar, almacenar; distribuir, conmutar son maneras del hacer salir lo oculto (...) Ahora bien ¿qué clase de estado de desocultamiento es propio de aquello que adviene por medio del emplazar que provoca? En todas partes se solicita que algo esté inmediatamente en el emplazamiento y que esté para ser solicitado para otra solicitación. Lo así solicitado tiene su propio lugar de estancia, su propia plaza. Lo llamamos las existencias. La palabra dice aquí más y algo más esencial que solo «reserva». La palabra «existencias» alcanza ahora rango de un título (...) Lo que está en el sentido de existencias ya no está ante nosotros como objeto (Heidegger, 1994, 19).

Hemos indicado hasta este momento la forma en que la técnica, tanto antigua como moderna, en su imperar presupone como rasgo ontológico fundamental la verdad entendida como $\alpha \lambda \eta ́ \theta \varepsilon \iota \alpha$, es decir, como sacar de lo oculto trayendo a la luz, sea al ente o bien sea las energías de la naturaleza. El motivo originario del interrogar heideggeriano era el desocultar la esencia de la técnica. En una forma amplia, podría indicarse que dicha esencia de la técnica radica en la $\alpha \hat{\lambda} \eta \dot{\theta \varepsilon \iota} \alpha$ en tanto que determina lo que sea la técnica misma en su acaecer griego o moderno. A pesar de esto, el interrogar de Heidegger va más allá de este hecho, desentrañando la esencia misma de la técnica moderna como Ge-stell. Con dicha noción se piensa aquello que llama al hombre a desocultar las energías de la Naturaleza a través de su provocación y explotación. Ge-stell, como aquello que esencia en la técnica moderna, es la interpretación de la Naturaleza como fuente de energía y, por ello, abierta al

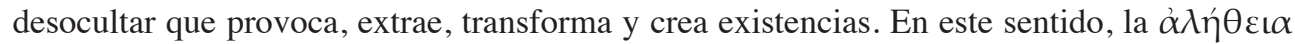
que violenta a la Naturaleza, presupone una torsión en dicho concepto (Naturaleza), en la medida en que desplaza la фúoıs griega -que materializaba el desocultar de modo más originario- a fuente de energía. La esencia de la técnica moderna es la Ge-stell que llama al hombre a ser amo y señor de la Naturaleza: "A aquella interpelación que provoca, que coliga al hombre a solicitar lo que sale de lo oculto como existencias, lo llamamos ahora la estructura de emplazamiento (Ge-stell)" (Heidegger, 1994, 23). Así, desde aquí y sólo desde aquí es pensable el imperio de las ciencias exactas durante la modernidad, no porque éstas abran paso a la esencia de la técnica moderna, sino porque la esencia de la técnica moderna, al concebir a la Naturaleza como fuente de energía, actúa como condición de posibilidad para el posterior cálculo y precálculo de los fenómenos naturales. 
Podríamos señalar que, dentro de los límites de la reflexión heideggeriana, el aspecto indicado representa una de las dos caras de la moneda. La otra cara, apunta a lo que Heidegger denomina el peligro de la época técnica. Dicho peligro consiste en un doble aspecto: por un lado, al ser llamado el hombre en el aquí y ahora por un modo de desocultar que violenta la Naturaleza, es posible que el hombre se ciegue ante formas de la $\alpha \lambda \eta ́ \theta \varepsilon \iota \alpha$ que se mueven más allá del horizonte de la Ge-stell; esto es, que olvide que el modo originario

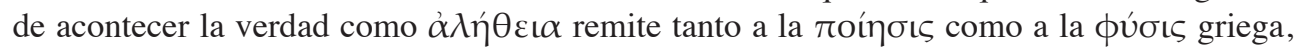
y no es únicamente el traer al aparecer objetos disponibles, es decir, existencias.

El segundo aspecto se encuentra referido a la posibilidad latente de que el hombre mismo termine reducido a simple existencia; esto es, a objeto disponible para el uso y correcto funcionamiento del mundo occidental. La técnica moderna desoculta en tanto que trae a la luz al ente como parte de un almacén en donde reposan los objetos para el momento en que necesiten. El hombre, que pone en marcha este modo de acontecer la verdad, corre el peligro radical de que su vida quede reducida -tal cual ocurre con los entes- a simple objeto disponible.

\section{La salida ante el peligro}

De acuerdo a lo hasta aquí dicho, podría intuirse erróneamente que Heidegger, al abordar el problema de la técnica, no piensa con la misma radicalidad con que expone el análisis, una manera de sobreponerse ante el peligro técnico-moderno que asecha al hombre. No obstante, esto no es así. Antes bien, nos ofrece de manera tentativa una forma de hacer frente al imperio de la técnica moderna y, con ello, de sobreponernos al peligro que ronda. La salida ofrecida por Heidegger lleva por nombre serenidad y, a partir de este instante intentaremos, dentro de los límites de lo que nos sea posible, abordarla brevemente.

El punto de partida que debemos tomar, es la caracterización de la vida cotidiana que ofrece Heidegger (2002) en la conferencia conmemorativa por la muerte de Conradin Kreutzer, publicada bajo el título de La serenidad. En dicha conferencia, Heidegger expone un análisis acerca del desarrollo de la técnica moderna que evidencia elementos argumentales centrales de su reflexión en torno al tema, coincidiendo con lo dicho en La pregunta por la técnica. Así, caracteriza la época contemporánea -época atómica- por el desarrollo incomparable de la tecnología en Occidente. Dicho progreso técnico, lo sitúa aquí en la misma fuente que en la conferencia trabajada previamente, a saber: en el establecimiento de una esencia particular de la técnica, la cual ordena y dirige la configuración posterior de la ciencia moderna y de los aparatos. Lo propio de la esencia de esta técnica, dice, es la particular comprensión que ofrece de la Naturaleza en tanto que la concibe como fuente de material energético:

Esta revolución radical de nuestro modo de ver el mundo se lleva a cabo en la filosofía moderna (...) La naturaleza se convierte así en una única estación gigantesca de gasolina, en fuente de energía para la técnica y la industria modernas (Heidegger, 2002, 23).

El despliegue del dispositivo implica que el individuo se inserte en sus dinámicas. En este sentido, Heidegger coincide nuevamente con lo dicho en La pregunta por la técnica. No obstante, el análisis que realiza en La serenidad respecto de la relación hombre-técnica 
moderna tiene como foco principal de atención ya no el hombre como el que provoca, sino que piensa al sujeto desde su cotidianidad respecto de la técnica; es decir, piensa la vida atravesada por los aparatos. De aquí se deriva lo que denominará Heidegger la condición de desarraigo propia del hombre moderno, en la medida en que se encuentra desgajado de su tierra natal (Heimat); esto es, de su tradición, del ámbito cultural y del espacio público en que ha nacido y crecido. Aunque no vayamos a detenernos en consideraciones más amplias en torno a la difícil temática de la tierra natal, quisiéramos dejar indicado esto en las palabras del mismo Heidegger:

Muchos alemanes perdieron su tierra natal, tuvieron que abandonar sus pueblos y ciudades expulsados de su suelo natal. Otros, cuya tierra natal les fue salvada, emigraron sin embargo y fueron atrapados en el ajetreo de las grandes ciudades (...) Se volvieron extraños a ella $i$ Y los que permanecieron en ella? En muchos aspectos están mucho más desarraigados que los exiliados. Cada día a todas horas están hechizados por la radio y la televisión (...) Todo esto con los instrumentos técnicos de información estimula, asaltan y agitan hora tras hora al hombre -todo esto le resulta hoy más próximo que el propio campo en torno al caserio (...) más próximo que la usansa y las costumbres del pueblo; más próximo que la tradición del mundo en que ha nacido (...) el arraigo del hombre está hoy amenazado en su ser más íntimo (Heidegger, 2002, 21).

De lo comentado en las líneas anteriores no es posible extraer del pensamiento heideggeriano una especie de romanticismo pre-tecnológico. Heidegger no coloca a la técnica moderna, a su esencia y su manifestación en artefactos, como una expresión maléfica del demonio. En los textos expuestos, coincide en afirmar el carácter no satánico de la técnica moderna y su esencia. Antes bien, señala la importancia que tienen los aparatos técnicos en la vida del individuo, facilitando sus labores diarias. Con esto, Heidegger afirmará entonces que, ante el doble peligro que se agiganta por el imperio de la técnica moderna, es preciso dar paso, por un lado, a la serenidad y, por otro, a la apertura al misterio. La primera (la serenidad), es vista como un poner límite firme a la utilización de los aparatos, con el fin de salvaguardar al hombre del peligro de tornarse objeto de dominio técnico. En este sentido, con la serenidad se apunta a la posibilidad de decir sí y no al uso constante de artefactos, refrenándose con esto la capacidad colonizadora de la técnica moderna.

Entre tanto, la apertura al misterio invita a pensar la esencia de la técnica moderna de forma meditativa. Esto es, que la apertura al misterio revela que el modo en que tiene lugar la $\alpha \lambda \eta ́ \theta \varepsilon \iota \alpha$ en el seno de la Ge-stell no es el único, y que su empoderamiento genera tanto dominio de la Naturaleza como posible dominio del hombre por el hombre. La apertura al

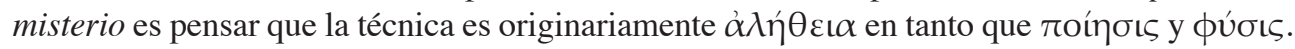

Así las cosas, el doble peligro mencionado en La pregunta por la técnica articula una doble posibilidad de encarar el predominio de la Ge-stell en el aquí y ahora del acontecer mundial, bajo las figuras de la serenidad y la apertura al misterio. Antes que fatalismo y negación, encontramos en Heidegger una comprensión radical y, por tanto, renovadora de la técnica. Coincidimos, en este sentido, con lo indicado por Xolocotzi (2009): 
Más allá de los detalles epocales que encontramos en torno al despliegue de la técnica, para Heidegger queda claro que el carácter maniobrante que en la técnica contemporánea llega a su climax, filosóficamente visto, no debe hundirnos en un pesimismo irremediable, sino más bien se abre el origen de su pureza. El maniobrar de nuestras vivencias que ahora rige la relación con el mundo deja ver, pues, el soterramiento inicial de la verdad como alétheia y en tal develamiento se desoculta el camino de Occidente. La relación con la técnica contemporánea no conlleva entonces ningún fatalismo, ni la tematización heideggeriana indica una resignación en torno al destino. Más bien se prepara el camino para otro modo de estar en el mundo y por ello otro modo de pensar (60-61. La cursiva es nuestra).

\section{Heidegger en perspectiva: acerca de la Serenidad}

Una vez recorrido un trecho breve que nos intenta acercar de manera panorámica al pensamiento heideggeriano en torno al problema de la técnica, el parágrafo final pretende invitar a pensar en "perspectiva" algunos de los elementos que han sido destacados aquí acerca del problema de la técnica moderna. Siendo precisos a este respecto, nuestra última parada intentará dar cuenta de una posible actualización en clave ética de la noción de serenidad expuesta por Martin Heidegger. De esta manera, y siguiendo el análisis desarrollado por Klaus Held (2009), intentaremos poner de relieve la forma en que es posible pensar a la serenidad heideggeriana como un modo nuevo de acontecer la virtud de la mesura

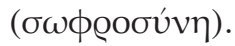

Held comenta que en la antigua tradición griega existía un conjunto de cuatro virtudes esenciales: la prudencia, la mesura, la justicia y la valentía. Tanto la mesura como la valentía eran ubicadas por Aristóteles en su Ética nicomáquea como el punto medio existente entre dos vicios opuestos. Dicho en clave aristotélica: la virtud ética debe ser definida como el justo medio entre el exceso y el defecto de la acción. En este orden de ideas, resulta necesario señalar que Held reemplaza la categoría de exceso y defecto propias del vocabulario aristotélico, por el concepto de sentimiento. Dentro de la categoría de sentimiento ubica el entusiasmo extremo respecto de una cosa y la desazón radical respecto de lo mismo que provoca entusiasmo. En la medida en que la mesura resulta ser el término medio idóneo respecto de dos sentimientos excluyentes, necesariamente variará en relación del cambio de contenido de los sentimientos.

Ahora bien ¿Cuáles son esos sentimientos que expresan en la época contemporánea los extremos opuestos? Siguiendo a Heidegger, Held indica que uno de los rasgos característicos de la contemporaneidad globalizada es la preeminencia de la técnica moderna en los distintos ámbitos de la vida humana. Llevando el empoderamiento de la técnica moderna en el mundo occidental hasta sus consecuencias extremas, dice que los sentimientos excluyentes variaron históricamente en función de la técnica; así, el entusiasmo extremo se encuentra materializado en la confianza y fe radical que se tiene en el progreso sustentado sobre la base del desarrollo técnico. Entre tanto, en la posición contraria al entusiasmo, esto es, en la desazón y desconfianza radical, se puede ubicar el temor respecto del desarrollo incontenible de la técnica moderna. El testimonio histórico posterior a la primeria mitad del siglo XX revela las consecuencias indeseables que ha acarreado el desarrollo tecnológico en el mundo 
y en la naturaleza. En este sentido, podríamos afirmar entonces que los dos sentimientos fundamentales entre los cuales se debate la $\sigma \omega \phi \varrho o \sigma u ́ v \eta$ en el aquí y ahora del acontecer mundial, responden a problemas de tipo ambiental. Esto se evidencia en la siguiente afirmación de Held: "No me interesará, sin embargo, abordar primeramente a este [el giro], sino abordar la pregunta por una actitud adecuada frente al problema actual del medio ambiente" (Held, En: Xolocotzi y Godina (Coords.), 2009, 15). De este modo, dice respecto de los dos sentimientos: "Uno de estos sentimientos es el temor a las consecuencias de la técnica para el medio ambiente. La posibilidad de transformar el mundo con los meidos de la técnica moderna produce hasta ya adentrados en el siglo XX un entusiasmo por el crecimiento y el progreso" (Held, En: Xolocotzi y Godina (Coords.), 2009, 15). Así las cosas, lo acontecido en el mundo Occidental con el despliegue ilimitado de la técnica moderna genera una posición ambivalente a la hora de evaluar su desarrollo. Por una parte, se tiene el deseo y la fe en el progreso, a la vez que se teme por los daños ambientales que genera. En una mano, la confortabilidad cada vez mayor de la vida; en la otra, la naturaleza violentada por el hombre. Por esta razón, la solución la ubica Held en la consecución de un sentido históricamente nuevo de la virtud de la mesura, que permita, al nutrirse de la aporía histórica de la técnica moderna, evitar el desarrollo extremo entre ambos sentimientos.

Held llama progresistas a los que se vinculan con el primer tipo de sentimiento, mientras que los segundos son denominados conservadores. Los progresistas buscan el mayor dominio posible de la totalidad del mundo a la par que pretenden con esto mejorar las condiciones materiales de la vida humana. Los conservadores abogan por una defensa de lo otrora establecido, en oposición al progreso. En medio de esta situación se inserta la serenidad como modo histórico actual de la mesura ¿cómo acontece esto?

Held señala que la disputa generada por la desmesura inherente a la técnica moderna, tiene como elemento que late de fondo al voluntarismo. Una voluntad de tendencia hacia el infinito es lo que atraviesa de lado a lado la disputa entre progreso y temor. Una voluntad quiere la permanencia de lo pasado, mientras que otra tiende hacia un progreso infinito que busca lo mejor. El decurso histórico del mundo occidental ha declarado como victoriosa la voluntad tendiente al infinito. Indica Held que, previo a la modernidad, no existía una tendencia hacia el progreso inacabado. De este modo, sólo con ella acontece que el empoderamiento de la técnica conduce irremediablemente hacia un futuro ideal, por vía del conocimiento científico. Es en este instante donde tiene cabida la caracterización heideggeriana de la serenidad. Vale indicar aquí que, si bien Kalus Held fija su atención no en la conferencia trabajada en el segundo acápite de este artículo sino en el diálogo redactado en 1945 por Heidegger, esto no implica necesariamente que la categoría de la serenidad presente una ruptura entre texto y texto. Antes bien, intentaremos mostrar cómo lo dicho en la conferencia se corresponde con lo analizado por Held en Debate en torno al lugar de la serenidad. De un diálogo sobre el pensamiento en un camino de campo. En este último texto, Heidegger plantea que el pensamiento occidental es, en esencia, voluntad. Refiriéndose a Kant dice que el pensamiento, como representación, en medida final es querer, es decir, voluntad "No obstante, el pensar, concebido tradicionalmente como representación (Vorstellen), es un querer; también Kant concibe el pensar así cuando lo caracteriza como espontaneidad. Pensar es querer (wollen) y querer es pensar" (Heidegger, 2002, 36). 
Frente a la tendencia voluntarista de la tradición moderna occidental en la que la historia se ha edificado sobre el concepto de querer lo mejor, identificando esto mejor con el progreso hacia el infinito, Heidegger propone un nuevo modo de materializarse la voluntad. De acuerdo a lo dicho por Held, el voluntarismo progresista y el temor al dominio tecnológico sólo son superables en la consecución de un término medio, esto si tiene lugar el establecimiento de un nuevo modo histórico de la voluntad. Por lo tanto, pensar la voluntad desde una nueva órbita implica pensar la mesura atendiendo a las condiciones históricas particulares del siglo. Esta nueva voluntad que niega el voluntarismo moderno será para Heidegger una voluntad del no-querer: "Y por eso, como respuesta a la pregunta sobre lo que yo propiamente quiero, en la meditación sobre el pensar, le contesté: quiero el no-querer" (Heidegger, 2002, 36). Esta nueva voluntad quiere el no-querer. Dicho en otras palabras: la técnica moderna y la época fundada en ella quieren el progreso infinito. Por su parte, la nueva voluntad no quiere lo contrario del progreso, como es el caso de los conservadores; antes bien, el no-querer de la nueva voluntad es mucho más radical en cuanto quiere el noquerer mismo, es decir, que su querer se contrapone al querer mismo, se opone a la voluntad moderna en cuanto tal, quiere el no-querer.

A esta voluntad del no-querer la llama Heidegger en el diálogo serenidad. Pensado desde términos éticos el planteamiento heideggeriano, querer el no-querer abre la puerta a una nueva forma de la mesura en la medida en que no asume una posición orientada respeto de los extremos opuestos mismos. Esto es, no es un querer el progreso o querer lo pasado. No se alinea con la tendencia hacia lo infinito o con la protección de lo que nos heredó el ayer. Es, simplemente, una forma del querer que busca el término medio entre ambas posiciones.

Esto acontece, en tanto que la serenidad que quiere el no-querer es capaz de decir «sí» y «no». Habíamos visto, en la exposición de la conferencia, que la serenidad puede ser entendida como la capacidad que tienen los hombres de hacer frente a los aparatos y a la esencia de la técnica moderna, escogiendo el momento en que se permite que ellos tengan lugar en nuestra vida. Así, la serenidad limita el poder de dominio de la técnica moderna y de su esencia en la medida en que establece una frontera demarcada entre el sí que le da acceso y el no que la deja fuera de juego, en tanto que los aparatos técnicos no nos colocan en posición de servidumbre respecto de ellos. Del mismo modo, nos arriesgamos aquí a afirmar, vinculando lo dicho en el diálogo y la conferencia, la serenidad tomada como ese sí y no es capaz de decir sí al voluntarismo moderno a la vez que es capaz de decir no a éste cuando se considere necesario hacerlo. La voluntad del no-querer puede querer el no-querer y, en tanto que límite de la voluntad, diría no a la voluntad moderna. A la vez, esa misma voluntad del no-querer puede decir sí, abriendo un espacio al voluntarismo que tiende al infinito. Cada momento de la serenidad, en tanto que término medio, debe decidir ese sí y no en momentos y situaciones concretas. En cada caso variará, por lo cual no existe una regla o norma que determine el deber-ser de la serenidad. Es el "en cada caso ahora de la situación" lo que se pondrá en juego desde la serenidad, cuando se la asume en sentido ético. A esto se refiere Klaus Held cuando nos remite a Kant en su texto: que la serenidad entra en juego en momentos específicos y que, dicho de forma moderna, es la facultad de juzgar la que debe determinar qué resulta bueno o malo, correcto o incorrecto hacer de acuerdo a cada contexto específico. De esta forma, podemos concluir resaltando el aspecto ético de la serenidad, en la medida en que se torna el justo medio -al decir sí o no- respecto de la 
esencia de la técnica moderna que, en vistas del progreso, domina y explota; esto en relación con el temor a las consecuencias generadas por dicho dominio:

Lo dicho vale también para la mesura requerida en la época técnica. Solamente en una determinada situación, en la que se trata de una concreta intervención técnica en lo previamente dado, se puede encontrar el justo medio entre progreso y conservación (Held, En: Xolocotzi y Godina (Coords.), 2009, 25-26).

\section{A modo de conclusión: nota crítica}

Para concluir, y una vez indicados los aspectos esenciales del análisis heideggeriano de la técnica moderna, además de la posible actualización de la serenidad, pensada con Held como una actualización de la mesura griega, es menester poner de relieve indicativamente dos interrogantes cruciales que se desprenden de esta lectura:

1. Para Klaus Held, la serenidad puede asociarse a un modo histórico en que acontece la $\sigma \omega \phi \varrho o \sigma u ́ v \eta$; sin embargo, es importante tener en cuenta que toda virtud ética se retrotrae

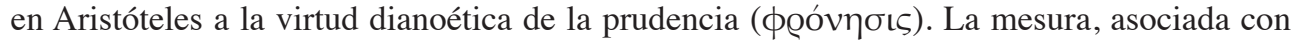
la serenidad, se analiza en función de escoger lo adecuado, lo mejor, en cada caso concreto.

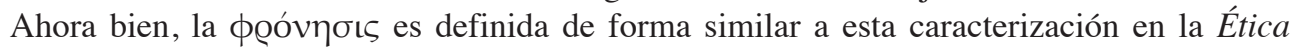
nicomáquea. De hecho, la distinción entre política y prudencia se encuentra en el carácter particular de la prudencia respecto de la elección de lo bueno y malo éticamente hablando, de acuerdo a la circunstancia de cada cual. En contraste con esto, la política apunta al bien de la polis. En este orden de ideas, y en tanto que la mesura presupone la prudencia, tal cual lo indica el Estagirita en E.N. VI, 5, 1140b 10 ss.: "Y es a causa de esto por lo que añadimos el término moderación al de prudencia, como indicando algo que salvaguarda la prudencia", sería adecuado interrogarse por el modo en que la serenidad se asociaría no sólo

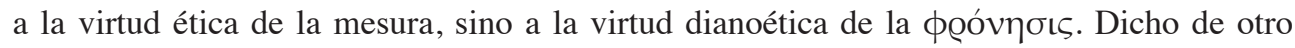
modo: habría que preguntarse por la posibilidad de que Gelassenheit pueda ser vista como una actualización tardía de la prudencia aristotélica.

2. Por otro lado, es importante pensar el modo en que podría tener lugar, como concreción histórica específica, la serenidad en tanto que expresión contemporánea de la

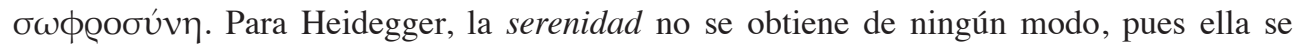
le otorga al hombre en el tránsito del querer al no-querer (Parece provenir de la contrada en tanto que se está abierto, a la espera de ella). Como el pensar es querer, la serenidad se encuentra más allá de los límites de la voluntad y del pensar, porque se edifica sobre la base del desacostumbramiento de la voluntad. Para Aristóteles, el contenido ético de una acción se encuentra relacionado con un ordenamiento/direccionamiento del deseo. El deseo, a su vez, se divide en voluntad, apetito e impulso. El deseo recto se ubica en el radio de acción de la voluntad, por ello en las acciones voluntarias es que es posible pensar el contenido ético. Consideramos que, en un sentido amplio, el carácter ético de la acción presupone, en Aristóteles, una forma de la voluntad pensada desde la elección. No obstante, y aunque la serenidad implique un modo del querer, en dicho querer prima el no. Por esta razón, sería menester analizar cómo se relacionan específicamente el carácter voluntario de la acción ética en Aristóteles con una serenidad que se otorga y no se despierta por simple elección 
humana. Dicho de otro modo: es importante pensar en detalle el modo en que una virtud ética puede tener lugar más allá de la frontera de la libre elección.

\section{Referencias}

Aristóteles (1988), Acerca del alma, Madrid: Gredos.

Aristóteles (2007), Ética nicomáquea, Madrid: Gredos.

Heidegger, Martin (1994), "La pregunta por la técnica”. En: Conferencias y artículos, Barcelona: Serbal.

Heidegger, Martin (1994), “Ciencia y meditación”. En: Conferencias y artículos, Barcelona: Serbal.

Heidegger, Martin (1995), Caminos de bosque, Madrid: Alianza.

Heidegger, Martin (1997), Ser y tiempo, Santiago de Chile: Editorial Universitaria.

Heidegger, Martin (2003), Aportes a la filosofía: acerca del evento, Bs. As.: Biblos.

Heidegger, Martin (2008), Problemas fundamentales de la filosofía. «Problemas» selectos de «lógica», Granada: Comares.

Held, Klaus (2009), "La serenidad como virtud de la época técnica”. En: Xolocotzi, Ángel y Godina, Célida (Coord.). La técnica ¿orden o desmesura?, México: Los libros de Homero.

Másmela, Carlos (2009), "Heidegger, el ensamblaje del Ge-stell en la técnica moderna" En: Xolocotzi, Ángel y Godina, Célida (Coord.). La técnica ¿orden o desmesura?, México: Los libros de Homero.

Volpi, Franco (2010), Martin Heidegger. Aportes a la filosofía, Madrid: Maia.

Volpi, Franco (2012), Heidegger y Aristóteles, Bs.As.: Fondo de cultura económica.

Xolocotzi, Ángel (2009), “Técnica, verdad e historia del ser". En: Xolocotzi, Ángel y Godina, Célida (Coord.). La técnica ¿orden o desmesura?, México: Los libros de Homero.

Xolocotzi, Ángel; Gibu, Ricardo; Huerta, Vanessa \& Veraza, Pablo (2014), Heidegger, del sentido a la historia, México: Plaza y Valdés. 
